\title{
A comparison of risky sexual behaviours between circumcised and uncircumcised men aged 30-44 years in Botswana.
}

\author{
Galekgatlhe Bailey Balekang, Kakanyo Fani Dintwa
}

Ministry of Health, Research.

\begin{abstract}
:
Background: The principal mode of HIV transmission in Southern Africa is through sexual intercourse, and this has prompted uptake of safe male circumcision. Engaging in risky sexual behaviour by circumcised men increases the risks of acquiring HIV, though male circumcision coupled with preventive behaviour reduces this risk.

Objective: To compare the factors associated with risky sexual behaviour among circumcised and uncircumcised men in Botswana.

Methods: Nationally representative data from the Botswana AIDS Impact Survey III were used. A sample of 313 sexually active men was used. The data was analysed by cross-tabulation and logistic regression.

Results: The study revealed that uncircumcised men (odds ratio, 5.711) were more likely to have sex while intoxicated with alcohol compared to circumcised men. Low levels of education (odds ratio, 8.736), urban residency (city/town: odds ratio, 1.238 and urban village: odds ratio, 1.098) were more likely to influence risky behaviour (more than one sexual partner) for circumcised men. The results also show that marital status (never married) (odds ratio, 1.947) influences risky behaviour (having sex while intoxicated with alcohol) among uncircumcised men.

Conclusion: Low level of education, place of residence and alcohol consumption influences risky sexual behaviour for both circumcised and uncircumcised men. Policies and programmes should thus focus on the attitudes underlying sexual behaviour.

Keywords: Risky sexual behaviours, circumcised, uncircumcised men, 30-44 years, Botswana.

DOI: http://dx.doi.org/10.4314/ahs.v16i1.14

Cite as: Balekang GB, Dintwa KF. A comparison of risky sexual behaviours between circumcised and uncircumcised men aged $30-44$ years in Botswana. Afri Health Sci. 2016;16(1): 105-115. http:/ / dx.doi.org/10.4314/abs.v16i1.14
\end{abstract}

\section{Introduction}

Randomized controlled trials indicate that medically performed male circumcision significantly reduces men's risk of acquiring HIV through sexual intercourse ${ }^{1}$. The principal channel of interpersonal HIV transmission in southern Africa is through sexual intercourse, which prompted WHO and UNAIDS to recommend increased male circumcision in the countries in this region ${ }^{2}$. As a result, many countries started mass male circumcision campaigns. In Botswana, the "Safe male circumcision programme" was launched by the Ministry of Health in $2009^{3}$; the Government aims to circumcise nearly 500000

\section{Corresponding author:}

Galekgatlhe Bailey Balekang,

Ministry of Health, Research

Email: balekang@gmail.com men over 5 years in an effort to prevent the spread of HIV.

Although male circumcision decreases the risk of acquiring HIV, the incidence of AIDS will not necessarily fall if the lower risk of acquiring HIV is associated with a higher propensity for risky sexual behaviour. Thus, if circumcised men believe that circumcision reduces the risk of infection, they may respond by more risky behaviour, commonly referred to as "risk compensation", although a randomized control trial did not show strong evidence of risk compensation among circumcised men in Rakai, Uganda. In another study, little difference was found between circumcised and uncircumcised men in terms of reducing risky sexual behaviour after receiving counselling ${ }^{4}$. Another study ${ }^{5}$ reports that male circumcision provides some level of protection against acquiring HIV, comparable to what a vaccine of high efficacy would have achieved. The results of another randomized control trial 
on 'male circumcision for prevention of heterosexual acquisition of HIV in men' reveal that there is strong evidence that medical male circumcision reduces the acquisition of HIV by heterosexual men by between $38 \%$ and $66 \%$ over 24 months $^{6}$.

According to ${ }^{7}$, educated individuals are more knowledgeable about the risks of having unprotected sex, having more than one sexual partner and having sexual intercourse under the influence of alcohol than people with no education. Dintwa noted that the use of condoms was affected by motivation and a belief that information on the use of condoms and the dangers of HIV/AIDS did not apply to them. They further reported that age contributed to non-use of condoms, and older partners tended to use coercion to obtain unsafe sexual intercourse. A number of studies ${ }^{8-9}$ report that alcohol is strongly associated with decreased protective behaviours. According to Kathleen et $\mathrm{al}^{10}$ alcohol increases the pleasures of sex- ual intercourse and that there is therefore less motivation to use condoms under the influence of alcohol. Lack of knowledge about HIV status might also contribute to the non-use of condoms. For example, individuals who do not know their HIV status may have unprotected sexual intercourse because they consider that if they are already infected using a condom will not prevent them from attracting HIV anymore?.

The aforementioned risky sexual behaviours and lack of knowledge regarding HIV transmission could facilitate the spread of HIV. For successful HIV/AIDS prevention, it is important to study factors that contribute to risky behaviour among circumcised and uncircumcised men. For this, a coherent framework is needed. Sociodemographic factors such as age, education, marital status and knowledge about HIV/AIDS transmission and prevention influence the sexual behaviour of both circumcised and uncircumcised men (Figure 1).

Figure 1.Conceptual framework of factors associated with risky sexual behaviour among circumcised men Adapted from? .

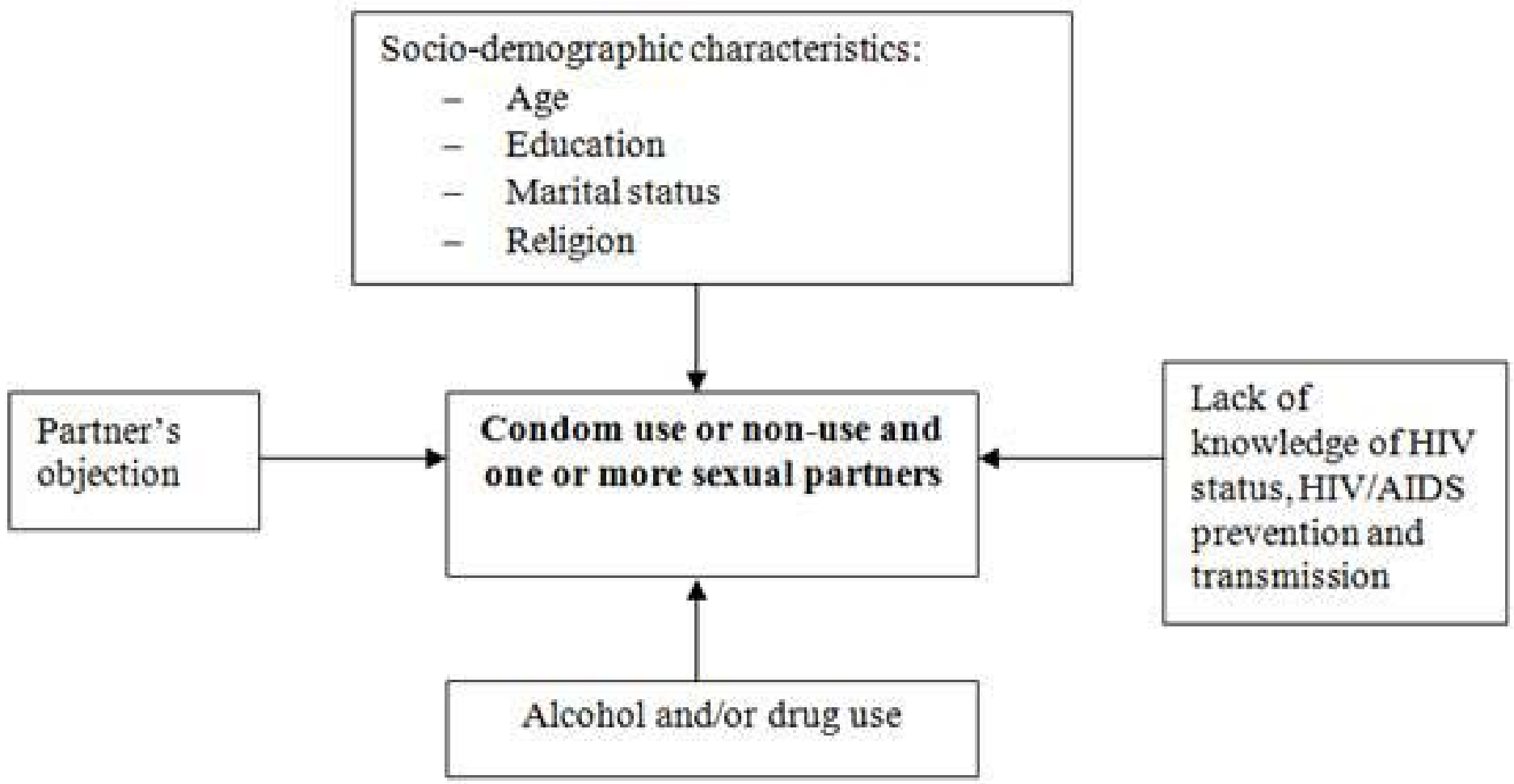

The aim of this study was to determine individual factors associated with risky sexual behaviour among circumcised and uncircumcised men aged 30-44 in Botswana. We investigated whether circumcised men had more than one sexual partner, did not always use a condom during sexual intercourse or had sexual intercourse under the influence of alcohol more often than uncircumcised men. We further investigated their knowledge about HIV infection. 


\section{Materials and methods}

The study is a secondary analysis of a subset of variables from the national Botswana AIDS Impact Survey III. Thus, we did not obtain informed consent from individual participants but this was obtained as part of the original wider study. During the BAIS III, informed consent was obtained from individuals who voluntarily agreed to take part in the study. They were assured of confidentiality and their right to withdraw from the study at any time they wished to. Ethical clearance was obtained from the Ministry of Health (Health Research and Development Committee).

Data was drawn from the Botswana AIDS Impact Survey III conducted in 2008, which was designed to allow comparisons of HIV prevalence rates, behaviour, knowledge, attitudes and other factors associated with the epidemic with estimates derived from previous surveys. For the survey, the primary sampling units were 4, 114 enumeration areas from the the 2001 Population and Housing Census, and the secondary sampling units were 8, 275 occupied households. Thus, the number of occupied households in a selected enumeration area served as the sampling frame for that enumeration area ${ }^{11}$.

For this study, a sample size of 313 circumcised $(\mathrm{N}=53)$ and uncircumcised $(\mathrm{N}=260)$ male respondents aged 30 44 years who had had sexual intercourse were selected to allow generalization of the results on use and non-use of condoms. According to Botswana AIDS Impact Surveys II of 2004 and Botswana AIDS Impact Surveys III of 2008, men aged 30-44 years had higher HIV prevalence than other age groups. This problem raises concern in the fight against the spread of HIV/AIDS in Botswana, hence the selection of the afore-said age group as study units in this study.

\section{Measures}

Several questions in the Botswana AIDS Impact Survey were used to address the study's objectives.

Number of sexual partners: Respondents were asked how many sexual partners they currently had. This binary variable was coded 1 for 'More than one' and 0 for 'One'. Having sexual intercourse while intoxicated: Respondents were asked if they had had sex while intoxicated. This binary variable was coded 1 for a 'Yes' response and 0 otherwise.
Condom use: Respondents were asked whether they had always used a condom with their partner in the past 12 months. This binary variable was coded 1 for a 'No' response and 0 otherwise. The implication here is that since there are high cases of multilple concurrent partnership in Botswana ${ }^{11}$, having sexual intercourse without using a condom is a risk factor for both married and never married as this provides a chance of contracting HIV. Non use of condom for the married, who have tested HIV negative does not become a risk factor only if none of the spouse have extra-marital affairs.

\section{Control variables}

The control variables used were age, education, marital status, place of residence and HIV testing. Knowledge about HIV infection was assessed from the answers to whether a healthy-looking person could be infected and whether there are any preventive measures against HIV infection. These variables were either dichotomous or categorical.

\section{Statistical methods}

Simple cross-tabulations were used to evaluate bivariate relations between independent and dependent variables (response and control, respectively). Logistic regression analysis was used to evaluate the relation between a group of predictor variables and the probability that individual factors were associated with risky sexual behaviour of circumcised and uncircumcised men, after control for other variables in the model. Logistic regression provides an interpretable linear model for a categorical dependent variable and allows the significance of a given predictor to be tested for, while controlling for all other predictors in the model ${ }^{12}$.

Separate logistic regression models were used to evaluate the effects of individual factors on the probability of engaging in risky sexual behaviour. For the $l^{\text {th }}$ individual, this model can be expressed as: $\ln P_{I}^{\prime\left({ }^{\prime}\right.} P_{i}{ }^{=} \beta_{0}{ }^{+} \sum \beta_{k} \chi_{k i}$

Where $P_{l}$ is the probability that the $l^{\text {th }}$ man will not use a condom, have more than one sexual partner, have a sexual partner who is 10 years older and have sexual intercourse under the influence of alcohol; $\beta_{0}$ is the baseline constant; $\chi_{i}$ is an array of $\kappa$ independent variables and $\beta$ is the corresponding vector of unknown regression coefficients. 
The SPSS-PC logistic programme was used to estimate regression coefficients by the maximum likelihood procedure $^{13,14}$.

\section{Results}

The characteristics of the study population are presented in Table 1, while Tables 2-4 show the factors associated with risky sexual behaviour among circumcised men.

The sample of this study as shown in Table 1 reveals that the majority of respondents both circumcised and uncircumcised; with more than one sexual partner; having had sexual intercourse intoxicated with alcohol; and who used condom inconsistently; fell in the age groups 30-34 years and 35-39 years. The majority of both circumcised and uncircumcised men with secondary education had more than one sexual partner compared to those with nonformal and primary education. With regards to marital status, the respondents (circumcised and uncircumcised) who were ever married had more than one sexual partner; had sexual intercourse when intoxicated with alcohol; and used condom inconsistently compared to the never married. It is evident from the results that the majority of respondents (circumcised and uncircumcised) residing in urban villages had more than one sexual partner compared to those residing in cities and towns, and rural villages. The majority of respondents (circumcised and uncircumcised) who believed that a healthy looking person cannot have HIV infection had more than one sexual partner and used condom inconsistently compared to those who believed that a healthy looking person can have HIV infection (refer to Table 1).

Table 1. Distribution of the respondents' engagement in risky sexual behaviour by selected socio-economic and demographic characteristics

\begin{tabular}{|c|c|c|c|c|c|c|}
\hline \multirow[t]{2}{*}{ Variable } & \multicolumn{3}{|c|}{ Circumcised } & \multicolumn{3}{|c|}{ Not circumcised } \\
\hline & $\begin{array}{l}\text { More than } \\
\text { one sexual } \\
\text { partner }\end{array}$ & $\begin{array}{l}\text { Having } \\
\text { sex when } \\
\text { intoxicated }\end{array}$ & $\begin{array}{l}\text { Inconsistent } \\
\text { condom use }\end{array}$ & $\begin{array}{l}\text { More than } \\
\text { one sexual } \\
\text { partner }\end{array}$ & $\begin{array}{l}\text { Having sex } \\
\text { when } \\
\text { intoxicated }\end{array}$ & $\begin{array}{l}\text { Inconsistent } \\
\text { condom use }\end{array}$ \\
\hline \multicolumn{7}{|l|}{ Age (years) } \\
\hline $30-34$ & $24(70.6 \%)$ & $3(10.3 \%)$ & $9(31.0 \%)$ & $96(68.1 \%)$ & $12(10.9 \%)$ & $23(20.7 \%)$ \\
\hline $35-39$ & $9(100.0 \%$ & $1(11.1 \%)$ & $4(44.4 \%)$ & $47(65.3 \%)$ & $12(22.6 \%)$ & $25(47.2 \%)$ \\
\hline $40-44$ & $3(42.9 \%)$ & $2(50 \%)$ & $2(50.0)$ & $23(59.0 \%)$ & $1(4.3 \%)$ & $6(26.1 \%)$ \\
\hline Total (N) & 36 & 6 & 15 & 166 & 25 & 54 \\
\hline \multicolumn{7}{|l|}{ Education } \\
\hline None & $0(0.0 \%)$ & $0(0.0 \%)$ & $(0.0 \%)$ & $2(50.0 \%)$ & $1(33.3 \%)$ & $1(33.3 \%)$ \\
\hline Primary & $6(60.0 \%)$ & $1(16.7 \%)$ & $3(50.0 \%)$ & $45(60.8 \%)$ & $7(14.3 \%)$ & $14(28.6 \%)$ \\
\hline Secondary & $15(78.9 \%)$ & $2(11.8 \%)$ & $4(23.5 \%)$ & $57(68.7 \%)$ & $4(6.2 \%)$ & $15(22.7 \%)$ \\
\hline Tertiary & $14(73.7 \%)$ & $3(16.7 \%)$ & $8(44.4 \%)$ & $40(78.4 \%)$ & $8(16.7 \%)$ & $14(29.2 \%)$ \\
\hline Total $(\mathrm{N})$ & 35 & 6 & 15 & 144 & 20 & 44 \\
\hline \multicolumn{7}{|l|}{ Marital status } \\
\hline Never married & $6(75.0 \%)$ & $1(14.3 \%)$ & $4(57.1 \%)$ & $21(95.5 \%)$ & $5(25.0 \%)$ & $13(65.0 \%)$ \\
\hline Ever married & $30(71.4 \%)$ & $5(14.3 \%)$ & $11(31.4 \%)$ & $145(63.6 \%)$ & $20(12.1 \%)$ & $40(24.1 \%)$ \\
\hline Total (N) & 36 & 6 & 15 & 166 & 25 & 53 \\
\hline \multicolumn{7}{|l|}{ Place of residence } \\
\hline City or town & $13(68.4 \%)$ & $3(16.7 \%)$ & $9(50.0 \%)$ & $45(72.6 \%)$ & $7(13.0 \%)$ & $16(29.6 \%)$ \\
\hline Urban village & $14(82.4 \%)$ & $2(14.3 \%)$ & $3(21.4 \%)$ & $61(66.3 \%)$ & $7(10.0 \%)$ & $16(22.9 \%)$ \\
\hline Rural village & $9(64.3 \%)$ & $1(10.0 \%)$ & $3(30.0 \%)$ & $60(61.2 \%)$ & $11(17.7 \%)$ & $22(34.9 \%)$ \\
\hline Total (N) & 36 & 6 & 15 & 166 & 25 & 54 \\
\hline \multicolumn{7}{|l|}{ HIV testing } \\
\hline Yes & $28(73.7 \%)$ & $4(12.5 \%)$ & $11(34.4 \%)$ & $113(71.1 \%)$ & $15(11.9 \%)$ & $39(30.7 \%)$ \\
\hline No & $8(66.7 \%)$ & $2(20.0 \%)$ & $4(40.0 \%)$ & $48(56.5 \%)$ & $9(16.4 \%)$ & $13(23.6 \%)$ \\
\hline Total (N) & 36 & 6 & 15 & 161 & 24 & 52 \\
\hline \multicolumn{7}{|l|}{$\begin{array}{l}\text { Healthy-looking } \\
\text { personcannot have }\end{array}$} \\
\hline \multicolumn{7}{|l|}{ HIVinfection } \\
\hline Yes & $32(78.0 \%)$ & $4(10.5 \%)$ & $12(31.6 \%)$ & $142(68.9 \%)$ & $17(10.5 \%)$ & $44(27.0 \%)$ \\
\hline No & $3(42.9 \%)$ & $2(66.7 \%)$ & $2(66.7 \%)$ & $8(33.3 \%)$ & $3(33.3 \%)$ & $3(33.3 \%)$ \\
\hline Total $(\mathrm{N})$ & 35 & 6 & 14 & 160 & 20 & 47 \\
\hline \multicolumn{7}{|c|}{$\begin{array}{l}\text { Nothing can be done to } \\
\text { prevent HIVinfection }\end{array}$} \\
\hline Yes & $35(72.9 \%)$ & $6(14.6 \%)$ & $14(34.1 \%)$ & $152(66.7 \%)$ & $23(13.3 \%)$ & $48(27.6 \%)$ \\
\hline No & $0(0.0 \%)$ & $0(0.0 \%)$ & $0(0.0 \%)$ & $4(80.0 \%)$ & $0(0.0 \%)$ & $3(75.0 \%)$ \\
\hline Total $(\mathrm{N})$ & 35 & 6 & 14 & 156 & 23 & 51 \\
\hline
\end{tabular}

Note: Inconsistencies in Total (N) for control variables is due to missing cases (Circumcised, Total $=53 \&$ Uncircumcised, Total $=260$ ) 
Individual factors associated with risky sexual behaviour among circumcised men

Age. In logistic regression analysis with control for potential confounders (education, marital status, residence and HIV testing), circumcised men aged 35-39years were $56 \%$ more likely to have had more than one sexual partner than those aged 40-44 years, and those aged 30-34 years were $23 \%$ more likely to have had more than one sexual partner than those aged 40-44 years. Uncircumcised men aged 30-34 and 35-39 years were slightly more than $50 \%$ less likely to have had more than one sexual partner than those aged 40-44 years.Fewer circumcised men aged 30-34 and 35-39 years than those aged 40-44 years had had sex when intoxicated and did not always use a condom, while the reverse was true for uncircumcised men in these age groups. The relationship for circumcised men was statistically significant $(\mathrm{p}<0.05)$ only for those aged 30-34 years and for having sex when intoxicated, but the findings for uncircumcised men were all statistically significant (Tables 2-4).

Table 2. Relative odds that circumcised and uncircumcised men had more than one sexual partner by selected individual characteristics: net effects model

\begin{tabular}{|c|c|c|c|c|c|c|}
\hline \multirow[t]{3}{*}{ Characteristic } & \multicolumn{3}{|c|}{ Circumcised } & \multicolumn{3}{|c|}{ Not circumcised } \\
\hline & \multirow[t]{2}{*}{ Odds ratio } & \multicolumn{2}{|c|}{$95 \%$ CI $\exp (\mathrm{B})$} & \multirow[t]{2}{*}{ Odds ratio } & \multicolumn{2}{|c|}{$95 \%$ CI $\exp (\mathrm{B})$} \\
\hline & & Lower & Upper & & Lower & Upper \\
\hline \multicolumn{7}{|l|}{ Age (years) } \\
\hline $30-34$ & 1.233 & 0.507 & 2.998 & $0.510 * *$ & 0.165 & 1.569 \\
\hline $35-39$ & 1.560 & 0.587 & 4.143 & $0.563 * *$ & 0.173 & 1.830 \\
\hline $40-44$ & 1.000 & - & - & 1.000 & - & - \\
\hline \multicolumn{7}{|l|}{ Education } \\
\hline None & 8.736 & 0.000 & - & $0.386 *$ & 0.036 & 4.108 \\
\hline Primary & $2.631 *$ & 0.917 & 7.755 & $0.420 *$ & 0.156 & 1.129 \\
\hline Secondary & 1.423 & 0.633 & 3.201 & $0.854 * *$ & 0.342 & 2.131 \\
\hline Tertiary & 1.000 & - & - & 1.000 & - & - \\
\hline \multicolumn{7}{|l|}{ Marital status } \\
\hline Never married & 1.187 & 0.062 & 22.861 & 1.947 & 0.425 & 8.913 \\
\hline Ever married & 1.000 & - & - & 1.000 & - & - \\
\hline \multicolumn{7}{|l|}{ Place of residence } \\
\hline City or town & 1.238 & 0.481 & 3.186 & 0.892 & 0.353 & 2.256 \\
\hline Urban village & 1.098 & 0.448 & 2.693 & $1.158 * *$ & 0.528 & 2.539 \\
\hline Rural village & 1.000 & - & - & 1.000 & - & - \\
\hline \multicolumn{7}{|l|}{ HIV testing } \\
\hline Yes & 0.786 & 0.326 & 2.332 & 0.358 & 0.114 & 1.123 \\
\hline No & 1.000 & - & - & 1.000 & - & - \\
\hline \multicolumn{7}{|c|}{$\begin{array}{l}\text { Healthy-looking } \\
\text { personcannot have } \\
\text { HIV infection }\end{array}$} \\
\hline No & 0.476 & 0.251 & 5.592 & 0.575 & 0.065 & 5.133 \\
\hline Yes & 1.000 & - & - & 1.000 & - & - \\
\hline \multicolumn{7}{|c|}{$\begin{array}{l}\text { Nothing can be done to } \\
\text { prevent HIV infection }\end{array}$} \\
\hline Yes & 1.695 & 0.000 & - & 0.208 & 0.011 & 3.830 \\
\hline No & 1.000 & - & - & 1.000 & - & - \\
\hline $\begin{array}{l}1.000 \text { is the refer } \\
* * * \text { significant at } \\
* * \text { significant at } \mathrm{p} \\
* \text { significant at } \mathrm{p} \\
\mathrm{CI} \text {, confidence in }\end{array}$ & & & & & & \\
\hline
\end{tabular}


Education. Having had more than one sexual partner was reported by all circumcised men but by only $50 \%$ of uncircumcised men with no education and by $84 \%$ of circumcised men and $61 \%$ of uncircumcised men with primary education. Having sex when intoxicated was reported by $14.3 \%$ of both circumcised and uncircumcised men with primary education. About $50.0 \%$ of circumcised men and $33.3 \%$ of uncircumcised men with no education reported inconsistent condom use.

Logistic regression analysis showed that circumcised men with primary education were 2.6 times more likely to have more than one sexual partner than those with tertiary education, and the relationship was statistically significant; uncircumcised men with no primary or secondary education were statistically significantly less likely to have had more than one sexual partner than those with tertiary education. Fewer circumcised men with lower levels of education than tertiary had had sex when intoxicated than those with tertiary education; uncircumcised men with no education were 2.9 times more likely to have had sex when intoxicated than those with tertiary education $(p<0.1)$. The level of education also affected the proportion of circumcised men who did not always use a condom during sexual intercourse; however, the only statistically significant relation was with secondary education.

Marital status. Of men who had never married, 75\% of those who were circumcised and $95.5 \%$ of those who were uncircumcised had had more than one sexual partner, whereas $71 \%$ of circumcised men and $64 \%$ of uncircumcised men who were ever married had had more than one sexual partner. About $14 \%$ of circumcised and $25 \%$ of uncircumcised men who had never married reported having had sex when intoxicated. More than half (57.1\%) of circumcised men and $65 \%$ of uncircumcised men who had never married used condoms inconsistently.
In logistic regression analysis, circumcised men who had never married were more likely than those who had ever married to have had more than one sexual partner, to have had sexual intercourse when intoxicated and to be inconsistent in the use of a condom during sexual intercourse, but the relations were not statistically significant. Nevermarried uncircumcised men were 1.9 times more likely to have had sexual intercourse when intoxicated than those who had ever married, and the relation was statistically significant. Uncircumcised who never married were 6.9 times more likely not to have used a condom consistently than those who were ever married $(p<0.01)$.

Residence. More circumcised men who had had more than one sexual partner lived in cities or towns $(84 \%)$ than in urban villages $(75.9 \%)$ or rural areas $(74.6 \%)$, whereas $73 \%$ of uncircumcised men who had had more than one sexual partner lived in cities and towns, with $66 \%$ in urban villages and 61\% in rural villages. Inconsistent use of a condom was reported by about half of circumcised men and almost $30 \%$ of uncircumcised men living in cities and towns.

In logistic regression analysis, circumcised men in cities, towns and urban villages were more likely to have had more than one sexual partner, to have had sexual intercourse when intoxicated and to be inconsistent in use of a condom during sexual intercourse than those living in rural villages. In contrast, circumcised men in urban villages were less likely to have inconsistent condom use than those in rural areas. Uncircumcised men were less likely to have had more than one sexual partner, to have had sexual intercourse when intoxicated and not always to use a condom during sex than those living in rural villages; however, uncircumcised men in urban villages were 1.2 times more likely to have had more than one sexual partner than those in rural areas $(\mathrm{p}<0.05)$. 
Table 3. Relative odds that circumcised and uncircumcised men had sex when intoxicated by selected individual characteristics: net effects model

\begin{tabular}{|c|c|c|c|c|c|c|}
\hline \multirow[t]{3}{*}{ Characteristic } & \multicolumn{3}{|c|}{ Circumcised } & \multicolumn{3}{|c|}{ Not circumcised } \\
\hline & \multirow[t]{2}{*}{ Odds ratio } & \multicolumn{2}{|c|}{$95 \%$ CI $\exp (\mathrm{B})$} & \multirow[t]{2}{*}{ Odds ratio } & \multicolumn{2}{|c|}{$95 \%$ CI $\exp (\mathrm{B})$} \\
\hline & & Lower & Upper & & Lower & Upper \\
\hline \multicolumn{7}{|l|}{ Age (years) } \\
\hline $30-34$ & $0.296 * *$ & 0.091 & 0.965 & $5.711 * *$ & 0.454 & 71.878 \\
\hline $35-39$ & 0.416 & 0.116 & 1.495 & $7.240 * *$ & 0.646 & 81.136 \\
\hline $40-44$ & 1.000 & - & - & 1.000 & - & - \\
\hline \multicolumn{7}{|l|}{ Education } \\
\hline None & 0.000 & 0.000 & & $2.973 *$ & 0.150 & 58.912 \\
\hline Primary & 0.777 & 0.211 & 2.857 & $0.551 * *$ & 0.125 & 2.427 \\
\hline Secondary & 0.823 & 0.271 & 2.504 & 0.255 & 0.061 & 1.067 \\
\hline Tertiary & 1.000 & - & - & 1.000 & - & - \\
\hline \multicolumn{7}{|l|}{ Marital status } \\
\hline Never married & 1.5782 & 0.000 & - & $1.947 * *$ & 0.425 & 8.913 \\
\hline Ever married & 1.000 & - & - & 1.000 & - & - \\
\hline \multicolumn{7}{|l|}{ Place of residence } \\
\hline City or town & 2.563 & 0.652 & 10.077 & 0.696 & 0.166 & 2.923 \\
\hline Urban village & 1.555 & 0.401 & 6.031 & 0.391 & 0.098 & 1.557 \\
\hline Rural village & 1.000 & - & - & 1.000 & - & - \\
\hline \multicolumn{7}{|l|}{ HIV testing } \\
\hline Yes & 0.826 & 0.225 & 3.031 & $0.358 * *$ & 0.114 & 1.123 \\
\hline No & 1.000 & - & - & 1.000 & - & - \\
\hline \multicolumn{7}{|c|}{$\begin{array}{l}\text { Healthy-looking } \\
\text { personcannot have } \\
\text { HIVinfection }\end{array}$} \\
\hline No & 3.681 & 0.000 & - & 0.575 & 0.065 & 5.133 \\
\hline Yes & 1.000 & - & - & 1.000 & - & - \\
\hline \multicolumn{7}{|c|}{$\begin{array}{l}\text { Nothing can be done to } \\
\text { prevent HIV infection }\end{array}$} \\
\hline Yes & 0.388 & 0.013 & 11.883 & $0.208^{*}$ & 0.011 & 3.830 \\
\hline No & 1.000 & - & - & 1.000 & - & - \\
\hline $\begin{array}{l}1.000 \text { is the refer } \\
* * * \text { significant at } \\
* * \text { significantat } \mathrm{p} \\
* \text { significant at } \mathrm{p} \\
\mathrm{CI} \text {, confidence in }\end{array}$ & & & & & & \\
\hline
\end{tabular}

HIV testing. About $80.9 \%$ of circumcised men and $55.8 \%$ of uncircumcised men who had not been tested for HIV had had more than one sexual partner. Furthermore, about $14 \%$ of circumcised men and $16.4 \%$ of uncircumcised men who had not had an HIV test had had sex when intoxicated, and almost $48 \%$ of circumcised men and $24 \%$ of uncircumcised men with no HIV test used a condom inconsistently.

In logistic regression analysis, both circumcised and uncircumcised men who had had an HIV test were less likely to have had more than one sexual partner, to have had sex when intoxicated and to use a condom inconsistently. None of the relations was statistically insignificant except for uncircumcised men with no HIV test (Tables 2-4). 


\section{Table 4. Relative odds that circumcised and uncircumcised men used condoms inconsistently by selected individual characteristics: net effects model}

\begin{tabular}{|c|c|c|c|c|c|c|}
\hline \multirow[t]{3}{*}{ Characteristic } & \multicolumn{3}{|c|}{ Circumcised } & \multicolumn{3}{|c|}{ Not circumcised } \\
\hline & \multirow[t]{2}{*}{ Odds ratio } & \multicolumn{2}{|c|}{$95 \%$ CI $\exp (\mathrm{B})$} & \multirow[t]{2}{*}{ Odds ratio } & \multicolumn{2}{|c|}{$95 \%$ CI $\exp (\mathrm{B})$} \\
\hline & & Lower & Upper & & Lower & Upper \\
\hline \multicolumn{7}{|l|}{ Age (years) } \\
\hline $30-34$ & 0.609 & 0.269 & 1.377 & $1.713 *$ & .373 & 7.860 \\
\hline $35-39$ & 0.677 & 0.284 & 1.616 & $3.981 * *$ & .882 & 17.978 \\
\hline $40-44$ & 1.000 & - & - & 1.000 & - & - \\
\hline \multicolumn{7}{|l|}{ Education } \\
\hline None & 0.385 & 0.02 & 7.346 & 1.452 & .091 & 23.245 \\
\hline Primary & 0.671 & 0.264 & 1.705 & 1.363 & .429 & 4.337 \\
\hline Secondary & $0.534 *$ & 0.255 & 1.12 & .842 & .304 & 2.334 \\
\hline Tertiary & 1.000 & - & - & 1.000 & - & - \\
\hline \multicolumn{7}{|l|}{ Marital status } \\
\hline Never married & 1.409 & 0.000 & . & $6.915 * * *$ & 2.106 & 22.709 \\
\hline Ever married & 1.000 & - & - & 1.000 & - & - \\
\hline \multicolumn{7}{|l|}{ Place of residence } \\
\hline City or town & $2.507 * *$ & 1.036 & 6.067 & .885 & .293 & 2.680 \\
\hline Urban village & 0.97 & 0.383 & 2.456 & $0.677 *$ & .245 & 1.866 \\
\hline Rural village & 1.000 & - & - & 1.000 & - & - \\
\hline \multicolumn{7}{|l|}{ HIV testing } \\
\hline Yes & 0.594 & 0.238 & 1.48 & 0.812 & 0.334 & 1.971 \\
\hline No & 1.000 & - & - & 1.000 & - & - \\
\hline \multicolumn{7}{|c|}{$\begin{array}{l}\text { Healthy-looking } \\
\text { personcannot have } \\
\text { HIVinfection }\end{array}$} \\
\hline No & 0.446 & 0.021 & 9.52 & .683 & .089 & 5.237 \\
\hline Yes & 1.000 & - & - & 1.000 & - & - \\
\hline \multicolumn{7}{|c|}{$\begin{array}{l}\text { Nothing can be done to } \\
\text { prevent HIV infection }\end{array}$} \\
\hline Yes & 0.553 & 0.005 & 57.21 & 1.332 & 0.000 & 0.000 \\
\hline No & 1.000 & - & - & 1.000 & - & - \\
\hline
\end{tabular}

Knowledge and attitudes. Circumcised and uncircumcised men who did not believe that a healthy-looking person could have HIV infection were less likely than those without this belief to have had more than one sexual partner, did not always use a condom during sexual intercourse and did not use a condom consistently. Circumcised men who did not believe that a healthy-looking person could be infected were, however, 3.68 times more likely to have had sexual intercourse when intoxicated. None of the relations was statistically significant.
Circumcised men who believed that something can be done to prevent infection with HIV were more likely to have had more than one sexual partner than those who did not believe this, while the opposite was found for uncircumcised men. Both groups of men who believed that something can be done to prevent infection with HIV were less likely to have had sex when intoxicated than those who did not believe this. The relation was statistically significant $(p<0.1)$ only for uncircumcised men who believed that HIV infection could be prevented (Tables 2-4). 


\section{Discussion and conclusion}

The data used in this analysis show that most circumcised men compared to uncircumcised men engage in sexual behaviour that can put them at risk of HIV infection; however, cicurmcised men aged 30-34 and 35-39 years were more likely to have had more than one sexual partner than uncircumcised men in the same age groups. This finding is consistent with the results of Auvert et $\mathrm{al}^{15}$, that circumcised men reported more sexual partners than uncircumcised men, and with Mah et $\mathrm{al}^{16}{ }^{16}$ who reported that the age group 30-34 years is the third most affected by HIV/AIDS.

Both circumcised and uncircumcised men who never married were more likely to have multiple concurrent partners, which has been recognized as a key driver of HIV transmission in Botswana. Concurrent partnerships have been described as the overlap of one or more sexual partnerships for 1 month or longer ${ }^{17}$, in the past 2 months ${ }^{18}$ or in the past 12 months ${ }^{19}$. Multiple partnerships are sequential or serial partnerships in which an individual engages in a sexual relationship with only one partner, with no overlap in time with subsequent partners ${ }^{19}$.

A similar finding by Shannon et $\mathrm{al}^{20}$ found that in terms of sexual risk practices in the previous 12 months, about $39 \%$ of men reported having multiple concurrent sexual partners in Botswana. Halperin et $\mathrm{al}^{21}$ commented that "beliefs or norms about masculinity and femininity often encourage men to have multiple partners and women to be passive and ignorant on matters of sexuality and reproduction". Men consider it acceptable to have extramarital affairs and use condoms only when they do not trust the other partner. Dintwa et $\mathrm{al}^{22}$ reported that drinking and intoxication decreased the likelihood of condom use in Norway and Germany.

In this study, uncircumcised men with no education were more likely than circumcised men to have had sex when intoxicated, and uncircumcised men with primary or no education were more likely not always to use a condom than circumcised men in the same education categories. Halperin et $\mathrm{al}^{21}$, however, found that higher education levels were associated with higher rates of inconsistent condom use and that respondents with a higher level of education lacked motivation for AIDS preventive behaviour. Culture plays a role in the formation of attitudes towards sex and HIV/AIDS, and previous work suggests that regressive cultural practices and traditions in African societies have perpetuated negative attitudes towards HIV/AIDS. Some such attitudes are that HIV does not exist, that condom use interferes with the pleasure of sex and that males are dominant in heterosexual relation$\operatorname{ships}^{23}$.

We found that circumcised men who did not believe that a healthy-looking person could have HIV infection were more likely than uncircumcised men to have had sexual intercourse when intoxicated. The implication is that there is less misconception about the transmission and prevention of HIV among uncircumcised than circumcised men. This finding is in accordance with the results of other researchers, although they did not specifically focus on circumcised and uncircumcised men. A study by Tabengwa et $\mathrm{al}^{24}$ showed that even people who are well informed about HIV transmission and prevention engage in risky sexual behaviour because they lack motivation or consider that this knowledge does not apply to them. ${ }^{25}$ observed that myths about HIV/AIDS have delayed changes in behaviour and have led to spread of the virus. Eaton and Riess et $\mathrm{al}^{26,27}$ found that circumcised men engage in risky sexual behaviour more often than uncircumcised men. Kibira et $\mathrm{a}^{28}$ added that circumcised men engaged in risky behaviour because they viewed circumcision as a vaccine against HIV and believed that they were protected. It should be noted that the data which was used in this study was collected in 2008 while the roll-out of "Safe medical male circumcision" started in 2009 in Botswana. The assumption is that all the men who took part in this study were not circumcised under the rollout campaign and were obviously not counselled about safe sex after circumcision. In other words, it cannot be generalised that men who get circumcised will engage in risky sexual behaviour compared to men who are not circumcised. Nevertheless, we must not turn a blind eye to the effects of beliefs about male circumcision and HIV prevention, as doing so may jeopardize current efforts to reduce HIV transmission through male circumcision.

Today, many interventions for the prevention of HIV transmission are based not on behavioural theory but on constructs that depend on the socio-cultural, political and economic situation and the stage of the epidemic. Policies and programmes should thus focus on the attitudes, 
underlying sexual behaviour and not only on awareness or knowledge about transmission and prevention of HIV/ AIDS. People may be informed about HIV transmission and prevention but still engage in risky behaviour because they lack motivation or believe that the knowledge does not apply to them.

\section{Limitations}

The study has several limitations. First, it is based on secondary data, therefore limiting the number of variables that could be collected, such as answers to the questions "Does alcohol intoxication enhance sexual pleasure?" and "Do you usually negotiate sex with your partner?" Such insight can be obtained only with qualitative approaches, such as in-depth interviews and focus group discussions. Secondly, the information collected was self-reported and is therefore subject to reporting errors and bias. Lastly, the study is based on cross-sectional data, so a causal relationship could not be identified. Therefore, interpretation of the results is limited to associations between variables rather than cause-and-effect relations.

\section{Conflict of interest:}

The authors declare no competing interest.

\section{References}

1. Gray, R.H., Godfrey, K., David, S., Frederick, M., Stephen, W., Fred, N., Noah, K., et al. "Male circumcision for HIV prevention in men in Rakai, Uganda: a randomised trial." The Lancet, 2007; Volume 369, Issue 9562, Pages 657 - 666, 24 February. DOI:10.1016/S01406736(07)60313-4.

2. World Health Organization. Country experiences in the scale-up of male circumcision in the Eastern and Southern Africa region: two years and counting. Geneva. 2009. 3. Ministry of Health. Botswana country report. Progress report of the national response to the 2001 declaration of comment on HIV/AIDS. Gaborone. 2010.

4. Bailey, R.C., Moses, S., Parker, C.B., Agot, K., Maclean, I., Krieger, J.N., Williams, C.F., Campbell, R.T., \& Ndinya-Achola, J.O. "Male Circumcision for HIV Prevention in Young Men in Kisumu, Kenya: A Randomised Controlled Trial." Lancet, 2007; Feb 24; 369(9562):643-656.

5. Auvert, B., Taljaard, D., Lagarde, E., Sobngwi-Tambekou, J., Sitta, R., \& Puren, A. " Randomized, controlled intervention trial of male circumcision for reduction of HIV infection risk: The ANRS 1265 trial. PLoS Medicine 2005; 2:e298
6. Siegfried, N., Muller, M., Deeks, J. J, and Jimmy, V. "Male circumcision for prevention of heterosexual acquisition of HIV in men."Cochrane Database Syst Rev 2 (2009).

7. Dintwa, K.F. 'Factors associated with non-use of condoms for sexually active Botswana women'. I Int Council Women's Health Issues; 2010; 31:37-52 PubMed .

8. Cooper, M. Lynne. "Alcohol and increased behavioral risk for AIDS." Alcohol Health \& Research World (1992). 9. White, H. R., Fleming, C. B., Catalano, R. F., \& Bailey, J. A. "Prospective associations among alcohol use-related sexual enhancement expectancies, sex after alcohol use, and casual sex."Psychology of Addictive Behaviors 23, no. 4 (2009): 702.

10. Kathleen, M., Nopkersorn, T., Sweat, Y., Swaengdee, Y., Mastro, T.D., \& Weniger, B.G. 'Alcohol consumption, brothel attendance, and condom use: Normative expectations among Thai military conscripts.' Medical Anthropology Quarterly; 1996; 10(3), 402-423.

11. Republic of Botswana, "Botswana AIDS Impact Survey III, 2008", Central Statistics Botswana, Gaborone, 2009.

12. DeMaris, A. Logit modeling: practical applications. London: Sage. 1992.

13. Hosmer, D.W. Jr. \& Lemeshow, S. Applied logistic regression. New York: John, Wiley \& Sons, Inc.; 1989.

14. Letamo, G., \& Rakgoasi, D. "Factors associated with non-use of maternal health services in Botswana." Journal of Health, Population and Nutrition; 2003; 21: 40-47.

15. Auvert, B., Taljaard, D., \& Lagarde, E. Randomized, controlled intervention trial of male circumcision for reduction of HIV infection risk: The ANRS 1265 Trial. PLoS Med; 2005; 2(11): e298. PubMed

16. Mah, T. \& Halperin, D.T. 'Concurrent sexual partnerships and the HIV epidemic in sub-Saharan Africa: the evidence to move forward.' AIDS and Behavior 14, no. 1 (2010): 11-16.

17. Colvin, M., Abdool Karim, S.S., Connolly, C., Hoosen, A.A., \& Ntuli, N. 'HIVinfection and asymptomatic sexually transmitted infections in a rural South African community.' International journal of STD \& AIDS 9, no. 9 (1998): 548-550.

18. Setswe, G. 'Why is MCP important in HIV prevention?' Paper presented at a UNAIDS consultation on MCP, 17 September 2008. Pretoria: Human Sciences Research Council. Available at www.hsrc.ac.za.

19. Carter, M.W., Kraft, J.M., \& Koppenhaver, T. 'A bull cannot be contained in a single kraal': concurrent sexual 
partnerships in Botswana. AIDS Behav; 2007; 11(6):822830.

20. Shannon, K., Leiter, K., Phaladze, N., Hlanze, Z., Tsai, A. C., Heisler, M., \& Weiser, S. D. Gender inequity norms are associated with increased male-perpetrated rape and sexual risks for HIV infection in Botswana and Swaziland. PLoS One, 2012: 7(1), e28739. PubMed

21. Halperin, D. \& Epstein, H. 'Concurrent sexual partnerships help to explain Africa's high HIV prevalence: implications for prevention.' Lancet; 2004; 364(9428):4-6. 22. Dintwa, K.F. 'Education and the spread of HIV/ AIDS in Botswana.' Population Studies Working Paper. Gaborone, University of Botswana; 2008; No. 4:13.

23. Hassoun, J., Traeen, B., Stigum, H., \& Zantedeschi, E. 'Pre-sexual alcohol consumption and use of condoms-A European cross-cultural study.' Culture, Health and Sexuality; 1996; 5: 439-454.

24. Tabengwa, M, Menyatso, T, Dabutha, S, Awuah, M, Stegline, C. 'Human rights, gender and HIV/AIDS: anal- ysis of the existing legal system and its shortcomings.' " In Republic of Botswana: report of the First National Conference on Gender and HIV/AIDS, pp. 21-23. 2001. 25. Letamo, G. "Gender dimensions in misconceptions about HIV/AIDS prevention and transmission in Botswana." " African Journal of AIDS Research 6, no. 2 (2007): 193-198.

26. Eaton, L., \& Kalichman, S.C. 'Behavioural aspects of male circumcision for the prevention of HIV infection.' Curr HIV/AIDS Rep; 2009; 6(4):187 -193. PubMed 27. Riess, H.T., Achieng, M.M., Otieno, S., Ndinya-Achola, J.O., \& Bailey, C.R. 'When I was Circumcised I was Taught certain things: Risky Compensation and Protective Sexual Behaviour Among Circumcised Men in Kisumo, Kenya.' PloS ONE, 2010; 5(8).

28. Kibira, S.P.S., Nansubuga, E. \& Tumwesigye, N. M. 'Male circumcision, sexual behaviour, and HIV status in Uganda' (Demographic Health Survey Working Papers). Washington DC: United States Agency for International Development. 2013. 